\title{
Community Regulation in Noise Control Towards Less Noise City
}

\author{
Purnami N*1, Helmi F1, Melyani $V^{1}$, Anissa DF1 and Arifianto D $^{2}$ \\ ${ }^{1}$ Department of Otorhinolaryngology Head and Neck Surgery, University of Airlangga, \\ Indonesia \\ ${ }^{2}$ Department of Engineering Physics, Institut Teknologi Sepuluh Nopember, Indonesia
}

Research Article

Volume 4 Issue 2

Received Date: July 15, 2019

Published Date: August 01, 2019

DOI: $10.23880 /$ ooaj-16000182

*Corresponding author: Nyilo Purnami, Faculty of Medicine, Department of Otorhinolaryngology Head and Neck Surgery, Universitas Airlangga, Dr. Soetomo General Hospital, Indonesia, Tel: +62315501648; Email: nyilo@fk.unair.ac.id

\section{Abstract}

Background: An increase in the noise of a region closely related to industrial areas and technological developments. However, these conditions are still slightly considered so that the impact on people who are vulnerable to hearing loss. Therefore, it is necessary to control the noise in the community.

Objectives: To identifying some of the noisy potential locations and levels of community hearing in some locations.

Methods: This study uses analytical observational designs that taken in vocational high schools, tourist attractions, entertainment venues, workplaces, highways, and hospitals. The measurement of noise by using Sound Level Meter and hearing level using Audiometry.

Results: The intensity of the sound achieves multiple check results could reach up to $85 \mathrm{~dB}$ or more. Noise at vocational high school (101 dB), East Java police station (115-128 dB), Highways (78-78 dB), Tourist Venues (88-97 dB), and several locations in hospitals such as water pumps (104 dB), boiler (96 dB), kitchen (99 dB), incinerator (101 dB), grinding (113 $\mathrm{dB}$ ), and workshop location (102 dB). Increased hearing levels of more than $25 \mathrm{~dB}$ in East Java Police School (37\%), Vocational School (61\% class, 51\% class III), and some Hospital locations such as sanitation (29\%), kitchen (48\%), and workshop location (50\%).

Conclusion: The data collection on potential locations of noise and the level of community hearing in some locations provides a picture of the dangers of noise. The noise setting in the community is important to implement and optimize health and safety management to makes a safety city.

Keywords: Noise; Hearing loss; Hearing level; City safety

Abbreviations: NIHL: Noise-Induced Hearing Loss; OSHA: Occupational Safety and Health Administration; WHO: World Health Organization; HCP: Hearing
Conservation Progam; HPDs: Hearing Protection Devices; PEL: Permissible Exposure Level. 


\section{Otolaryngology Open Access Journal}

\section{Introduction}

The hearing is an important sense for individuals in carrying out daily activities. The sound is a part that inseparable from the listening process. In everyday life, a loud voice is harmful to hearing even if it is only briefly expelled. The sound affects the sensitive structures in the inner ear that cause sensory hearing loss. Long exposure to noise can become permanent and commonly known as Noise-Induced Hearing Loss (NIHL) [1,2]. Initially, the condition is temporary but if left will become permanent. NIHL can be prevented from using protective devices such as earplugs, ear muffs, helmets, or other protective devices that can prevent excessive exposure $[3,4]$. The problem encountered in the community is to apply for proper ear protection against noise exposure Based on Occupational Safety and Health Administration (OSHA) regulations the allowed noise at work is $85 \mathrm{~dB}$ for 8 hours [5]. In Indonesia, it has been regulated in accordance with Regulation of the Minister of Health of the Republic of Indonesia Number 70 of 2016 on Industrial Health Working Environment Standards and Requirements concerning noise level threshold. There are several studies that identify noise in some public locations such as in vocational high schools, tourist attractions, entertainment venues, workplaces, highways, and hospitals. Noise at that location averages above the set tolerance limit [6-8]. East Java is one of the fastest growing provinces of tenure and industry in Indonesia. Many potential locations are sources of noise. Because at this time, there is no sufficient data related to hearing the loss in some noise locations to serve as the foundation to realize the city safety free from noise. Thus, the researchers aimed to identify the level of noise and hearing levels of the community in some noisy locations.

\section{Methods and Materials}

This study uses analytic observational designs taken at vocational high schools, tourist attractions, entertainment venues, workplaces, highways, and hospitals. The number of subjects taken in audiometric measurements by100 students who participated from East Java police schools taken before and after training fired weapons, 74 students from vocational schools, and 58 workers from noisy environments, water pumps, boilers, kitchens, incinerators and workshops at Dr. Soetomo Hospital Surabaya, Indonesia. The measurement of noise using Sound Level Meter and hearing level using Audiometry.

\section{Results}

\section{Measurement of Noise Level}

The intensity of the noise ranges up to $85 \mathrm{~dB}$ and even more. The results of all measurements show that the source of noise was exposure to high doses every day. Noise in vocational schools during practice reached 101 $\mathrm{dB}$, compared to $55 \mathrm{~dB}$. The police school during shooting practice using weapons reaches 115-128 dB. Traffic noise on the highway was about 78-78 $\mathrm{dB}$ and the rides were around 88-97 dB. Some noise locations in hospitals such as $104 \mathrm{~dB}$ water pump, $96 \mathrm{~dB}$ boiler, $99 \mathrm{~dB}$ kitchen, 101 $\mathrm{dB}$ incinerator, $113 \mathrm{~dB}$ grinding, and $102 \mathrm{~dB}$ workshop.

\section{Hearing Measurements Level}

Hearing rate measurements show more hearing loss in the noisy area. Audiometric results with a hearing rate of more than $25 \mathrm{~dB}$ were found in $37 \%$ of students in the East Java Police School taken after training in firing weapons. In Vocational School, $61 \%$ of grade 1 students and $51 \%$ of grade 3 students have a hearing level above $25 \mathrm{~dB}$. Hearing levels of workers at several locations Dr. Soetomo Teacher Hospital Surabaya Indonesia found sanitation (29\%), kitchen (48\%), and workshop (50\%) had hearing levels above $25 \mathrm{~dB}$.

\section{Discussion}

Currently, excessive noise is increasing rapidly along with technological developments and busy environments. This poses a risk to the deterioration of individual hearing functions that are in the vicinity of the environment. If left unchecked it will cause other systemic problems. The number of NIHL patients will increase if existing regulations are not implemented [9]. The NIHL case should be prevented optimally. Workplace noise issues, public places, and recreation areas need to be given special attention when sound pollution occurs. In Indonesia already has regulation related to industrial work environment standard and requirement of health concerning noise level threshold. In the implementation in the community is still not optimal so it needs to be done an evaluation of the legislation related to the limits of the noise level of a region. Most countries of the World Health Organization (WHO) have adopted a special law aimed at reducing noise including intensity, frequency, and duration in an area/city that can harm society [10]. This study proves the tendency of exposure to excessive 


\section{Otolaryngology Open Access Journal}

noise in public and work areas. The data collected showed that exposure to high-dose daily noise at the site. According to the rules of prolonged exposure to noise that sounds louder than $85 \mathrm{~dB}$ is potentially harmful. The negative effect usually occurs at a frequency of $4000 \mathrm{~Hz}$ in the high-frequency area of the cochlea. The effect of the impulse noise is different from the continuing noise associated with its duration. Acoustic reflex triggered when exposed to noise more than $90 \mathrm{~dB}$. This mechanism provides partial protection to the inner ear to continue, but not for high-intensity sound impulses. Noise during the practice of firing a shotgun can penetrate the cochlea before the acoustic reflex is activated. The condition is associated with acoustic trauma and noise of more than $140 \mathrm{~dB}$ causes permanent and irreversible hearing loss $[10,11]$.

Prevention and conservation assistance programs need to be implemented according to the regulations. OSHA set about allowable noise exposure of only 8 hours each day with an intensity of $85 \mathrm{~dB}$. The presence of disorders in this study indicates more than just the allowable dose limits. This evidence demonstrates the need to apply Hearing Conservation Progam (HCP) at work, noisy environments, hospitals, and schools. The following programs of effective HCP include noise monitoring, engineering control, administrative control, worker education, selection, and use of Hearing Protection devices (HPDs), and periodic audiometric evaluations. HPDs should be able to reduce worker exposure to tolerable noise or permissible exposure level (PEL) [12].

There is no sign of danger for noise increase in noisy environments. Some information is given to protect people from the noise heard. Includes information about the noise level, the time allowed to live or work around the place and notify the noise hazard to educate the public. Promoting the Goals of Sound Hearing 2030 requires a strategy to reduce $90 \%$ of preventable hearing loss by 2030. To achieve this, comprehensive cooperation with all parties, such as the Government, the Ministry of Health, and non-governmental organizations and community participation is required. Implementation of pollution prevention regulations in the community can be achieved by optimizing the role of urban health and safety programs for inadequate noise [13]. Important points for achieving that goal with community education, publicizing through the media, parades using noiserelated, media promotion in the community. Working together to help manage the city's noise pollution levels with organizations for the prevention of hearing and hearing loss, such as deaf management (National
Committee of PGPKT) committees to coordinate activities with local committees in the situation [14].

Based on the regulation, the industry noise level is 70 $\mathrm{dB}$, Noise at the hospital/residence and in school is $55 \mathrm{~dB}$. This was indicating that in this study indicates excessive noise levels. That is evidence related to the trend of increasing the potential of people exposed to noise. Some educational materials on the noise hazard need to be provided to increase public awareness in the community.

\section{Conclusion}

There is consistency in the implementation of hearing conservation programs based on national regulations is still remain a problem. First, there is a need for urgent hearing prevention programs in the NIHL risk population from the occupational noise and recreational effects. Second, provides the necessary information to properly use the hearing protection device. Third, the at-risk population should have protection from deteriorating hearing levels with regular hearing tests and baseline data previously recorded. Lastly, record and report the NIHL prevalence that required for the evaluation of safety regulations

\section{References}

1. Yost WA (2013) Fundamentals of hearing: an introduction. $5^{\text {th }}$ (Edn.), Lieden, Boston, Brill, pp: 338.

2. Robinson T, Whittaker J, Acharya A, Singh D, Smith M (2015) Prevalence of noise-induced hearing loss among woodworkers in Nepal: a pilot study. Int J Occup Environ Health 21(1): 14-22.

3. Metidieri MM, Rodrigues HF, Filho FJ, Ferraz DP, Neto AF, et al. (2013) Noise-Induced Hearing Loss (NIHL): literature review with a focus on occupational medicine. Int Arch Otorhinolaryngol 17(2): 208-212.

4. Masterson EA, Bushnell PT, Themann CL, Morata TC (2016) Hearing Impairment among Noise-Exposed Workers-United States, 2003-2012. Morbidity and mortality weekly report 65(15): 389-394.

5. McLaren SJ, Page WH, Parker L, Rushton M (2013) Noise producing toys and the efficacy of product standard criteria to protect health and education outcomes. Int J Environ Res Public Health 11(1): 4766.

6. Ellingson RM, Gallun FJ, Bock G (2015) Measurement with verification of stationary signals and noise in 


\section{Otolaryngology Open Access Journal}

extremely quiet environments: measuring below the noise floor. J Acoust Soc Am 137(3): 1164-1179.

7. Yao C, Ma AK, Cushing SL, Lin VYW (2017) Noise exposure while commuting in Toronto-a study of personal and public transportation in Toronto J Otolaryngol Head Neck Surg 46(1): 62.

8. Tanaka T, Inaba R, Aoyama A (2016) Noise and lowfrequency sound levels due to aerial fireworks and prediction of the occupational exposure of pyrotechnicians to noise. J Occup Health 58(6): 593 601.

9. Nelson DI, Nelson RY, Concha-Barrientos M, Fingerhut M (2005) The global burden of occupational noise-induced hearing loss. Am J Ind Med 48(6): 446-458.

10. Donoghue AM, Frisch N, Dixon-Ernst C, Chesson BJ, Cullen MR (2016) Hearing conservation in the primary aluminium industry. Occup Med 66(3): 208214.

11. Kim J, Lee W, Won JU, Yoon JH, Seok H, et al. (2017) The relationship between occupational noise and vibration exposure and headache/eyestrain, based on the fourth Korean Working Condition Survey (KWCS). PloS one 12(5): e0177846.

12. Chadambuka A, Mususa F, Muteti S (2013) Prevalence of noise induced hearing loss among employees at a mining industry in Zimbabwe. Afr Health Sci 13(4): 899-906.

13. Varshney S (2016) Deafness in India. Indian Journal of Otology 22(2): 73-76.

14. Soetjipto D (2007) Komite Nasional Penanggulangan Gangguan Pendengaran dan Ketulian (PGPKT). 